\title{
Breakpoint analysis of Turner patients with partial Xp deletions: implications for the lymphoedema gene location
}

\author{
Catherine A Boucher, Carole A Sargent, Tsutomu Ogata, Nabeel A Affara
}

\begin{abstract}
Background-Turner syndrome is characterised by a 45,X karyotype and a variety of skeletal, lymphoedemic, and gonadal anomalies. Genes involved in the Turner phenotype are thought to be $\mathrm{X} / \mathrm{Y}$ homologous with the $\mathbf{X}$ genes escaping $\mathbf{X}$ inactivation. Haploinsufficiency of the SHOX gene has been reported to cause the short stature seen in Turner syndrome patients. More recently, mutations of this gene have been shown to be associated with other skeletal abnormalities, suggesting that haploinsufficiency of SHOX causes all the Turner skeletal anomalies. No such gene has yet been identified for the lymphoedemic features.

Methods-Fluorescence in situ hybridisation (FISH) analysis with PAC clones on nine patients with partially deleted $X$ chromosomes was performed.

Results/discussion-The Turner syndrome stigmata for each patient are described and correlation between the breakpoint and the phenotype discussed. A lymphoedema critical region in $\mathrm{Xp} 11.4$ is proposed and its gene content discussed with respect to that in the previously reported Yp11.2 lymphoedema critical region. (F Med Genet 2001;38:591-598)
\end{abstract}

Keywords: Turner syndrome; lymphoedema; Xp11.4

Turner syndrome ${ }^{1}$ has a world wide incidence of 1 in 2500 live female births and is characterised by a 45,X karyotype and a complex and variable phenotype. Typically, skeletal, visceral, gonadal, and soft tissue anomalies can be seen as well as miscellaneous features such as pigmented naevi and neurocognitive deficits. Prenatal lethality is also associated with Turner syndrome and only $1 \%$ of $45, \mathrm{X}$ fetuses survive to term. ${ }^{2}$

Short stature is the only invariant feature seen in Turner patients. Other skeletal stigmata seen include short neck, short 4th metacarpal, high arched palate, shield chest, and cubitus valgus. Seventy nine percent of patients with $45, \mathrm{X}$ show at least one of these skeletal features. ${ }^{3}$ A characteristic neurocognitive profile of deficits in visuospatial abilities, visuoperceptual abilities, motor function, non-verbal memory, executive function, and attentional abilities is also commonly seen in Turner patients. ${ }^{4}$ The visceral abnormalities include coarctation of the aorta and horseshoe kidney and are seen in $29 \%$ of $45, \mathrm{X}$ patients. Either primary amenorrhoea (associated with streak gonads) or secondary amenorrhoea (premature ovarian failure) are seen in $88 \%$ and $12 \%$ of $45, \mathrm{X}$ patients, respectively. In addition, distension of the main and tributary lymphatic ducts (as a result of lymphatic hypoplasia) and generalised lymphoedema are found in Turner patients. $^{5}$ It has been proposed that the distended cervical lymphatic system (cystic hygroma) results in the anomalies of the nuchal region, such as the webbed neck and low posterior hairline, while the generalised lymphoedema results in the peripheral anomalies such as the puffy hands and feet. These lymphatic stigmata are seen in $76 \%$ of 45 ,X patients and appear to resolve with age. ${ }^{35}$ Owing to the wide range of stigmata, it is thought that several $\mathrm{X}$ chromosome genes may play a role in Turner syndrome. As most $\mathrm{X}$ chromosome genes are subject to $\mathrm{X}$ inactivation, their expression will not be directly affected by X chromosome monosomy. Therefore it has been proposed that Turner genes escape $\mathrm{X}$ inactivation in females and are $\mathrm{X} / \mathrm{Y}$ homologous in males where the $\mathrm{Y}$ gene is functionally equivalent to the gene on the $\mathrm{X} .{ }^{6}$ Ferguson-Smith ${ }^{6}$ postulated that this did not apply to genes concerned with the gonadal phenotype because the inactive $\mathrm{X}$ chromosome is reactivated before meiosis and therefore both $\mathrm{X}$ chromosomes are active in oocytes. However, $\mathrm{X} / \mathrm{Y}$ homologous genes are now known to be involved in male infertility ${ }^{7}$ and therefore may play a role in female fertility and the gonadal anomalies found in Turner syndrome.

Comparison of the incidence of the stigmata in 45 ,X patients with that in partially sex chromosome deleted patients has led to several hypotheses. ${ }^{3}$ It was suggested that genes that play a role in the somatic stigmata are likely to lie in $\mathrm{Xp}$, whereas gonadal dysfunction is likely to be the result of poor pairing of the sex chromosomes in meiotic prophase. The severity of gonadal dysfunction is approximately proportional to the extent of deletion in terminal deletion patients, but appears mild in interstitial deletion cases. It has been postulated that proximal Yq is a critical region for the skeletal abnormalities ${ }^{89}$ and that the region in distal Yp between the pseudoautosomal boundary and sY45 is important for lymphoedema. ${ }^{10}$

SHOX was the first gene to be identified that is involved in the Turner syndrome phenotype. It lies in the pseudoautosomal region PAR1 and haploinsufficiency of this gene was first found to lead to growth failure both in Turner patients and in idiopathic short stature. ${ }^{11} 12$ Mutations and deletions of SHOX are also associated with Leri-Weill dyschondrosteosis, 
Table 1 Details of the patients' karyotype and phenotype. The lymphoedemic features are in bold

\begin{tabular}{lll}
\hline Patient & Karyotype & Turner stigmata \\
\hline 1 & $46, \mathrm{X}, \operatorname{del}(\mathrm{X})(\mathrm{p} 11.2)$ & $\begin{array}{l}\text { Webbed neck, short metaparcals, high arched palate } \\
\text { Equivocal webbed neck, nail dysplasia, high arched palate, cubitus valgus, pigmented naevi } \\
\text { None }\end{array}$ \\
3 & $46, \mathrm{X}, \operatorname{del}(\mathrm{X})(\mathrm{p} 11.21)$ & $\begin{array}{l}\text { Webbed neck, nail dysplasia, low hairline, puffy hands/feet, high arched palate, cubitus valgus, shield } \\
\text { chest, low set ears }\end{array}$ \\
4 & $46, \mathrm{X}, \operatorname{del}(\mathrm{X})(\mathrm{p} 21)$ & Nail dysplasia, low hairline, cubitus valgus \\
& $46, \mathrm{X}, \operatorname{der}(\mathrm{X}) \mathrm{t}(\mathrm{X} ; 2)(\mathrm{p} 11.22 ; \mathrm{p} 11.2)$ & Equivocal webbed neck, high arched palate, cubitus valgus, pigmented naevi \\
& $46, \mathrm{X}, \operatorname{der}(\mathrm{X}) \mathrm{t}(\mathrm{X} ; \mathrm{Y})(\mathrm{p} 11.2 / \mathrm{p} 11.4 ; \mathrm{q} 12 / \mathrm{q} 11.2)$ & Cubitus valgus, mild Madelung deformity, shield chest, pigmented naevi \\
6 & $46, \mathrm{X}, \operatorname{del}(\mathrm{X})(\mathrm{p} 11.3)$ & None \\
7 & $46, \mathrm{X}, \operatorname{del}(\mathrm{X})(\mathrm{p} 11.23)$ & Cubitus valgus, short metacarpals \\
8 & $46, \mathrm{X}, \operatorname{del}(\mathrm{X})(\mathrm{p} 11.21)$ & \\
9 & $46, \mathrm{X}, \operatorname{del}(\mathrm{X})(\mathrm{p} 11.4)$ & \\
\hline
\end{tabular}

which is a dominant disease characterised by short stature and skeletal dysplasia including Madelung deformity. ${ }^{13}{ }^{14}$ More recently, studies of SHOX using human embryos have detected expression in the middle portion of the arm around the distal end of the humerus, radius, and ulna and in some of the bones of the wrist. ${ }^{15}$

A

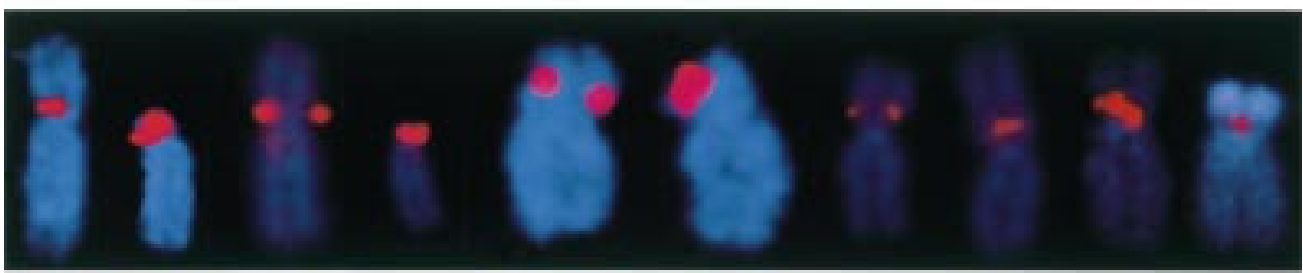

Similar expression patterns were detected in the lower limbs and expression was also detected in the pharyngeal arches. A de novo nonsense mutation in SHOX was shown to be associated with bilateral Madelung deformity, cubitus valgus, and short fourth metacarpals in one short stature patient. In a family with five short
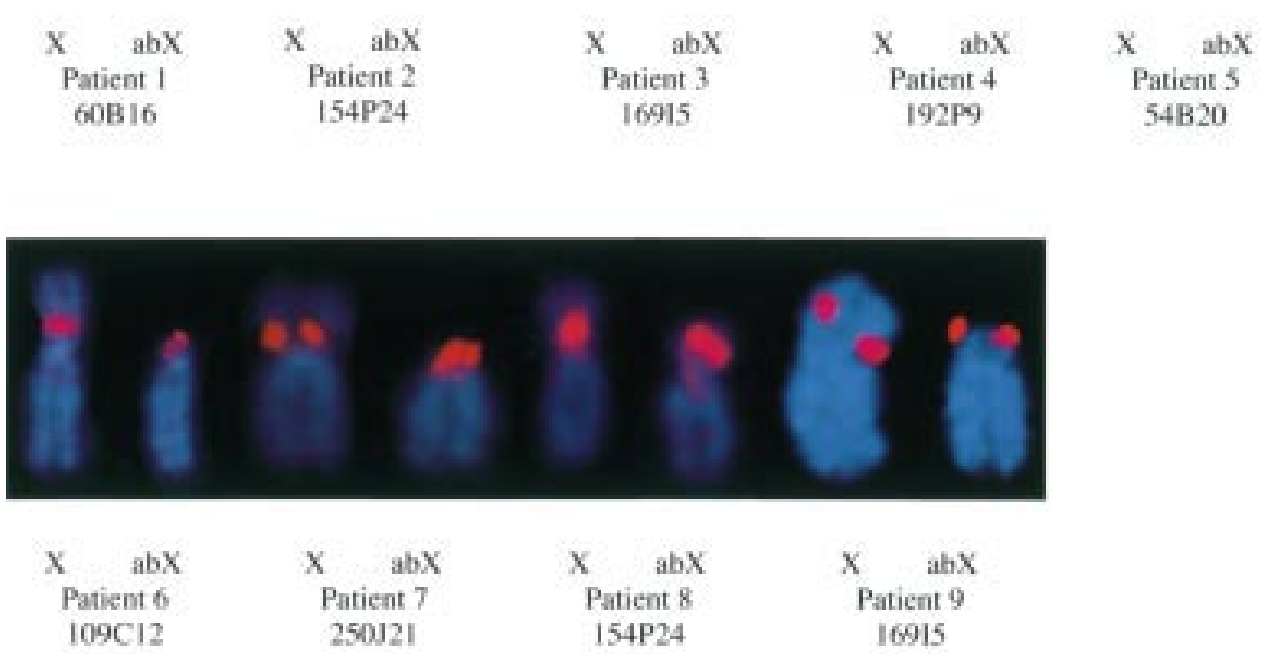

B

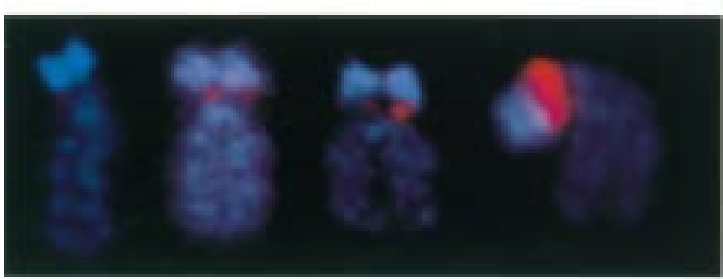

$\mathrm{abX}$

Patient 5

$156 K 7$ $a b X$

Patient 5

$211 \mathrm{G} 9$
$\mathrm{abX}$

Patient 5

272 N23
$\mathrm{abX}$

Patient 5

234D5
Figure 1 (A) Results of FISH with $X$ chromosome PAC clones, labelled with biotin (red signal), on the Turner syndrome patients' $X$ chromosomes (DAPI counterstained). The FISH result for the most distal positive PAC on the abnormal $X$ chromosome (abX) for each patient is shown. (B) Results of FISH with $Y$ chromosome PAC clones on the $\operatorname{der}(X) t(X ; Y)$ chromosome in patient 5. 


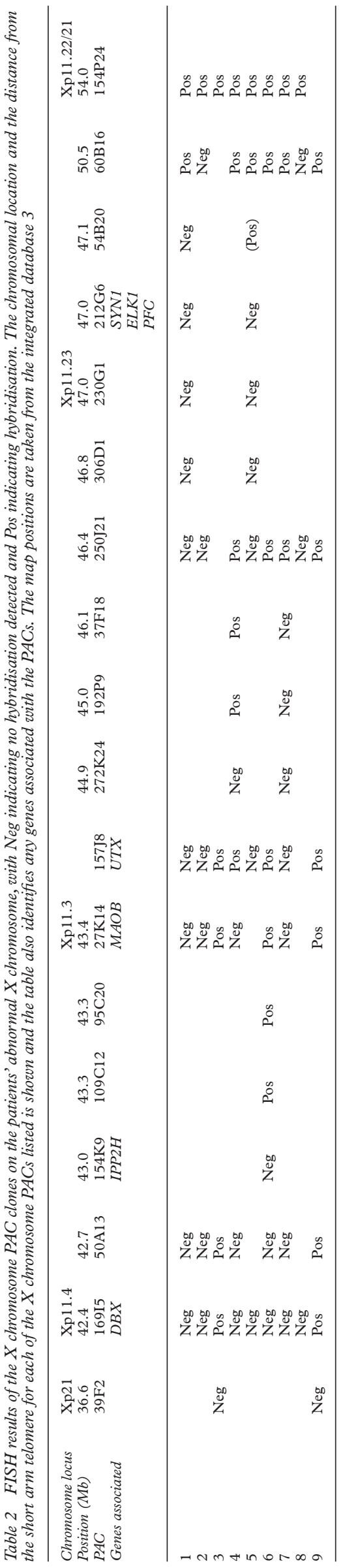

stature members, a varied phenotype was seen associated with a nonsense mutation of SHOX including short neck, scoliosis, and genu valgum. It also appears that gonadal oestrogens can modulate the phenotypic effects of SHOX haploinsufficiency. ${ }^{16}$ The expression studies and mutation analysis now make SHOX a strong candidate for all skeletal abnormalities seen in Turner patients but it is unlikely to play a role in the other Turner stigmata.

In an attempt to elucidate candidate genes for the soft tissue abnormalities, we have analysed the breakpoints in nine terminal Xp11 deletion patients with an apparently non-mosaic karyotype. Genotype/phenotype comparisons have been made and the location of candidate lymphogenic gene(s) discussed.

\section{Materials and methods}

PATIENTS

Subjects with an X chromosome short arm terminal deletion or unbalanced translocation were identified for this study. The karyotype was performed on 30-150 lymphocytes for each patient to evaluate non-mosaicism (table 1). All patients were short in stature and the other Turner stigmata identified in these patients are shown in table 1. Cell lines were prepared for each patient by EBV transformation of lymphocytes.

FISH

Metaphase preparations of each patient cell line were prepared. Normal female and male control lymphoblastoid cell lines were also used. Human genomic PACs from across Xp11 (from the RPCI1 library supplied by the UK HGMP Resource Centre and constructed by Pieter de Jong, Roswell Park Cancer Institute, Buffalo) were labelled with biotin by nick translation and hybridised to the metaphase preparations. The probes were detected using Cy3-avidin antibody (Amersham Pharmacia) and metaphases were DAPI counterstained. Images were captured using a Nikon Microphot-SA microscope equipped with CCD camera. IP-Lab Spectrum software with Smart Capture extension were used to normalise and enhance images. Adobe photoshop was used to extract the individual chromosomes from the metaphase images.

STS ANALYSIS

PCR using STS primers from across the Y chromosome was performed on $100 \mathrm{ng}$ genomic DNA from patient 5 . The markers used were sY17, sY58, sY62, sY72, GY8, sY81, sY84, sY85, sY86, sY90, sY97, sY102, sY116, sY117, sY118, sY119, sY121, sY122, sY124, sY125, sY126, sY127, sY128, sY130, sY132, sY134, sY136, sY138, sY140, sY142, sY144, sY146, sY148, sY150, sY152, sY154, and sY156 (primer sequences are detailed in Vollrath et $a l^{17}$ ) and by primers designed from the SMCY 5' UTR (forward: 5'gagataaacgct gaggacgc3', reverse: 5'ggtgcgtttctacggacatt3') and the SMCY 3' UTR (forward: 5'tttcttaggtt gcctccct3', reverse: 5'tcgcaggagaacactgaatgg3'. The PCR conditions used were as described in Jones et al. ${ }^{17}$ 


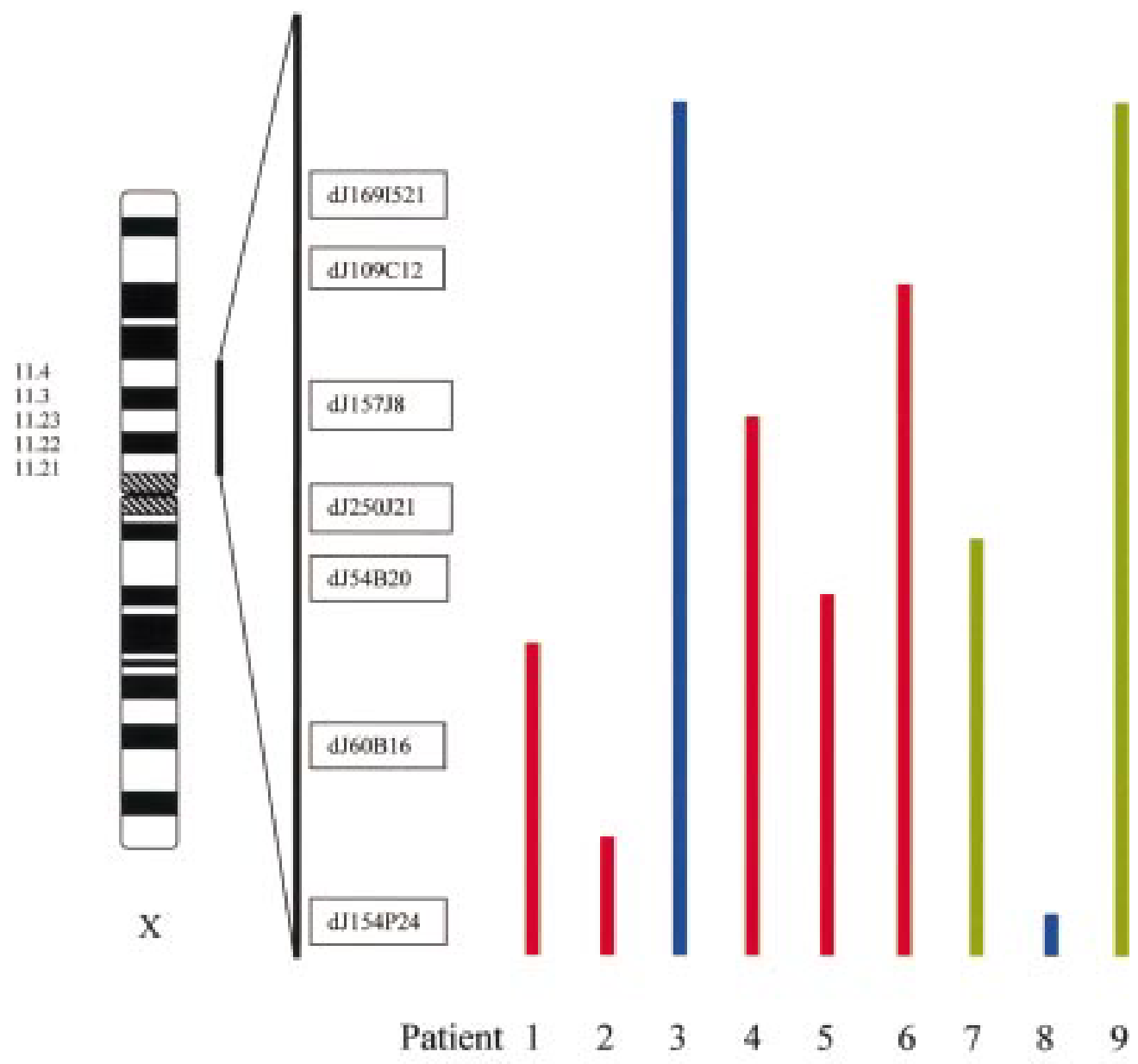

\section{No lymphoedemic or skeletal anomalies except short stature \\ Skeletal anomalies \\ Skeletal and lymphoedemic anomalies}

Figure 2 Illustration of the extent of the Xp present in the abnormal X chromosome of each patient and the presence/absence of skeletal and lymphoedemic features in each patient. The relative position of the hybridising PAC clones across Xp11 is also shown. Blue indicates that the patient shows no lymphoedemic or skeletal anomalies except short stature, green indicates that the patient shows only skeletal abnormalities, and red indicates that the patient presents with both skeletal and lymphoedemic stigmata.

MICROSATELLITE ANALYSIS

Microsatellite analysis of markers AFM238yc11, AFMa124xd9, AFMa183wf5, AFM256ze5, AFM276xf5, AFM168ya3, AFM119xd9, AFM248te9 AFM106xa3, AFM137xe11, AFMa230vc1, and AFM151xf6 was performed on the Turner patient genomic DNA. PCR reactions were performed on $500 \mathrm{ng}$ of patient genomic DNA in a $20 \mu$ total volume with $1 \times$ PCR buffer (HT Biotechnology), 12.5 pmol reverse and forward primer, $200 \mu \mathrm{mol} / 1$ dNTPs, 0.2 units Super Taq (HT Biotechnology), and $0.5 \mu \mathrm{mol} / 1$ [TAMRA]dUTP/2 $\mu \mathrm{mol} / 1$ [R110]dUTP or [R6G]dUTP with cycling conditions: $94^{\circ} \mathrm{C}$ for five minutes; 26 cycles of $94^{\circ} \mathrm{C}$ for one minute, $55^{\circ} \mathrm{C}$ or $57^{\circ} \mathrm{C}$ for one minute, $72^{\circ} \mathrm{C}$ for one minute; $72^{\circ} \mathrm{C}$ for 10 minutes. A total of $1.5 \mu \mathrm{l}$ PCR product together with $0.5 \mu \mathrm{l}$ GeneScan -350[ROX] were run on a $6 \%$ denaturing acrylamide gel on an $\mathrm{ABI} 373$ sequencer and the data analysed using GeneScan 672 software to score for heterozygosity.

DATABASE SEARCHES

PAC, BAC, microsatellite, and gene mapping data were made available through the Sanger Centre (http://www.sanger.ac.uk/HGP/ChrX/ mapping.shtml), the integrated database 3 (http://ixdb.molgen.mpg.de/), and NCBI mapviewer (http://www.ncbi.nlm.nih.gov/cgi-bin/ Entrez/maps.cgi?org=hum $\&$ chr $=\mathrm{X}$ ). Sequence data from PAC/BAC clones deposited in GenBank were analysed for homologies to known genes using the NIX program at the UK HGMP Resource Centre (http://menu.hgmp. mrc.ac.uk).

SCREENING OF THE PAC LIBRARY

The RPCI-1 PAC library was screened by PCR with STS markers sY124, sY125, and sY126 ${ }^{17}$ 
using PCR conditions as described in Jones et $a l .{ }^{18}$ The RPCI-1 PAC library was also screened for $S M C Y$ using the 5'UTR and 3'UTR primer pairs.

\section{Results}

The karyotype analysis of the patients suggested that their breakpoints were in Xp11 (except patient 3 with breakpoint in Xp21). In order to confirm the karyotype analysis and to refine the breakpoints further, FISH analysis was performed with a number of PACs from across this region. Fig 1 shows the normal and aberrant $\mathrm{X}$ chromosomes for each of the patients hybridised with the most distal PAC that shows signal on the aberrant chromosome. Table 2 details the position of the PAC clones relative to the $\mathrm{X}$ chromosome short arm telomere and the results of the FISH with the PACs on the patient abnormal X chromosome. Fig 2 illustrates both the extent of Xp chromosome present in each patient and the presence/ absence of skeletal and lymphoedemic features in each patient.

To confirm the PAC FISH data, patient DNA was amplified using microsatellite markers from across the region. For any given marker, the presence of two alleles (heterozygosity) suggested that both the normal and the aberrant X chromosomes contained the marker and therefore the breakpoint was distal. The presence of one allele was uninformative as the patient DNA could be either homozygous or hemizygous. The results of this analysis supported that of the FISH analysis (data not shown). No further information regarding the location of the patients' breakpoints was gained.

As patient 5 has an $\mathrm{X} ; \mathrm{Y}$ translocation, it was important to determine the extent of the $\mathrm{Y}$ material in this patient because a critical region for lymphoedema in $\mathrm{Yp}$ has already been defined. ${ }^{10}$ Genomic DNA from patient 5 and a normal male control was amplified using a series of STS markers from across the Y chromosome (including STSs designed for SMCY gene 5'UTR and 3'UTR) and typed for the presence or absence of each marker. All markers amplified the control DNA. All the markers typed from $\mathrm{Yp}$ and the proximal portion of $\mathrm{Yq}$ (up to and including sY124) were found to be absent in the DNA of patient 5 and sY125 and all the more distal markers were found to be present (data not shown). Therefore, it appeared that the breakpoint on the Y chromosome in patient 5 was between sY124 and sY125 with SMCY present and intact in patient 5 .

To confirm this result, FISH analysis was performed using PAC clones from across this region on the $\mathrm{Y}$ chromosome. The RPCI1 PAC library was screened using the STS markers sY124, sY125, sY126, and SMCY gene markers. STS content analysis was carried out on the clones isolated (table 3). DJ234D5 was found to be strongly positive on the structurally abnormal chromosome in patient 5, while dJ156K7, dY272N23, and dJ211G9 were found to be only faintly positive (fig 1 ). Thus,
Table 3 STS content of the Y chromosome PACs, with + indicating that the PAC was found to be positive for the marker

\begin{tabular}{|c|c|c|c|c|c|}
\hline \multirow[b]{2}{*}{$P A C s$} & \multicolumn{5}{|c|}{ Markers } \\
\hline & $s Y 124$ & SY125 & SMCY $3^{\prime}$ & SMCY 5' & $s Y 126$ \\
\hline $\mathrm{dJ} 272 \mathrm{~N} 23$ & + & & & & \\
\hline dJ156K7 & + & + & & & \\
\hline dJ232F18 & + & + & + & + & \\
\hline dJ211G9 & & & & + & \\
\hline dJ234D5 & & & & & + \\
\hline
\end{tabular}

the FISH data support the STS analysis for patient 5 .

\section{Discussion}

ANALYSIS OF PATIENT BREAKPOINTS

FISH analysis with PAC clones across Xp11.4 has defined the breakpoints in nine Turner patients. For patient 1 a much stronger signal with PAC dJ60B16 (the most distal positive PAC tested) was consistently detected on the abnormal X chromosome. This suggests that duplication has occurred in this region and it is speculated that this might affect the phenotype in this patient. For patient 5 a much weaker signal with PAC dJ54B20 was seen on the abnormal chromosome compared to that on the normal one. This suggests that the $\mathrm{X}$ chromosome breakpoint lies within the sequence covered by this PAC. Although the breakpoint on the Y lies close to $S M C Y$, the breakpoint on the $\mathrm{X}$ is approximately $7 \mathrm{Mb}$ more distal than SMCX. Patient 8 appears to have chromosomal material more distal to the most distal hybridising PAC, dJ154P24. Further refinement of the breakpoint in this patient will determine whether material is solely from the region between PAC dJ60B16 and dJ154P24 or whether the rearrangement involves other material from elsewhere in the genome, which is moderating the phenotype in this patient.

A high degree of variation of symptoms is seen with patients with similar deletions. As SHOX has been shown to be involved in many of the skeletal stigmata seen in Turner patients, it is likely that the skeletal phenotype seen in our collection of patients can be explained by deletion of SHOX on the abnormal X chromosome. As with the family described in ClementJones et $a l,{ }^{15}$ it is likely that the variation in symptoms seen may be because of the genetic background and/or oestrogen levels. ${ }^{16}$ However, there is no evidence to suggest that SHOX is involved in the lymphoedema stigmata. The simplest explanation for these symptoms is that haploinsufficiency of another single $\mathrm{X} / \mathrm{Y}$ homologous gene is causal and the variation is again because of genetic background. Alternatively, mosaicism may play a more important role in ameliorating the lymphoedema, as the high level of fetal lethality seen in 45 , X patients is likely to be caused by the extreme lymphoedema. Mosaicism, with some normal $46, \mathrm{XX}$ cells, is extremely prevalent in surviving 45 , X patients and it is likely that sufficient normal cells allow survival and may mask other symptoms depending on population numbers and cell type. 46,X,del(X)/46,XX mosaicism in lymphocytes must be extremely rare; it has 
been reported that it has never been seen in one laboratory, which has seen 5000 abnormal karyotypes. ${ }^{19}$ However, it might be more prevalent in the specific tissues associated with lymphoedema.

In order to locate the position of a gene responsible for the lymphoedema and related symptoms (webbed neck, low posterior hairline, puffy hands/feet, and nail dysplasia), only those patients with one or more of these stigmata were analysed. These are patients 1,2 , 4,5 , and 6 . Of these patients, patient 6 has the most distal breakpoint (between PACs dJ154K9 and dJ109C12). This suggests that the gene for the lymphoedema and associated stigmata lies distal to PAC dJ109C12.

A number of well documented and characterised contiguous deletion syndromes are associated with regions across $\mathrm{Xp}$. These include ichthyosis, Kallmann syndrome, Duchenne muscular dystrophy, and retinitis pigmentosa. Patients with these disorders do not show Turner-like symptoms and therefore the gene for lymphoedema is likely to lie outside the regions of $\mathrm{Xp}$ defined by the interstitial deletions seen in patients with these disorders. One such patient who has no Turner symptoms has been reported with deletion of DMD and OTC. ${ }^{20}$ This suggests that the gene responsible for the lymphoedema may be between OTC and dJ109C12.

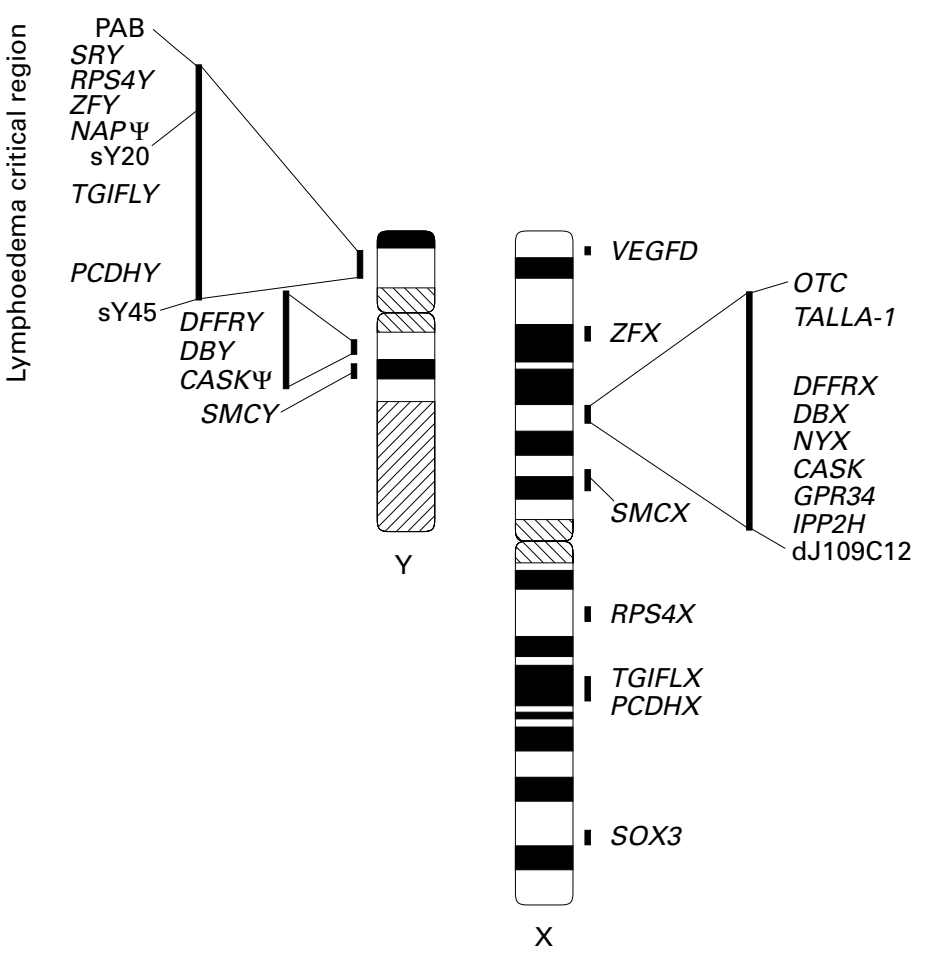

Figure 3 Ideograms of the $X$ and $Y$ chromosomes with the position of the lymphoedema critical region for both chromosomes indicated. The position of the pseudoautosomal boundary (PAB), the STS markers sY2O and sY45, the PAC clone df109C12, the $Y$ chromosome genes SRY, ZFY, RPS4Y, TGIFLY, PCDHY, DBY, DFFRY, and SMCY, and their X chromosome homologues SOX 3, ZFX, RPS 4X, TGIFLX, PCDHX, DBX, DFFRX, and SMCX, the X chromosome genes VEGF-D, OTC, TALLA-1, NYX, CASK, GPR34, and IPP2H, and the pseudogenes NAP $\Psi$ and $C A S K \Psi$ are also indicated.
OTHER MOLECULAR CYTOGENETIC STUDIES OF Xp DELETION PATIENTS

Three other molecular based studies have been carried out on terminal $\mathrm{Xp}$ deletion patients. Zinn et $a l^{21}$ looked at 28 apparent non-mosaic patients but only two subjects showed signs of lymphoedema and therefore no analysis was carried out on this trait. Short stature, ovarian failure, high arched palate, and autoimmune thyroid disease was mapped to Xp11.2-p22.1 in this study. Additionally, a second study with a similar grouping of patients looked at the neurocognitive function and found that the deficit in visuospatial/perceptive skills seen in Turner patients is mapped to PAR1, distal to PAC RPCI3-431I1.

A study by James et $a l^{19}$ investigated the breakpoints in $25 \mathrm{Xp}$ deletion cases with 17 showing a non-mosaic karyotype. Microsatellite analysis was carried out on the subjects and their parents to determine the extent of deletion of informative markers. Of the nonmosaic cases investigated, none presented with a webbed neck, two showed oedema, and one had a definite sign of low posterior hairline. The two oedema patients had breakpoints in $\mathrm{Xp22}$, while the low posterior hairline patient had the proximal breakpoint in Xp11.2.

INHERITED 46,X,DEL(X)

A few cases of inheritance of $46, \mathrm{X}, \operatorname{del}(\mathrm{X})$ have been reported. ${ }^{22-24}$ Such cases are much less likely to have any mosaicism, either $45, \mathrm{X}$ or $46, \mathrm{XX}$, which could ameliorate the phenotype. None of these cases show any signs of lymphoedema. The patient with the most proximal breakpoint has a terminal deletion and the breakpoint lies between $D M D$ and $C Y B B$ making a location for a lymphogenic factor proximal to DXS1242 (DMD) ${ }^{24}$

GENE CONTENT BETWEEN OTC AND PAC DJ109C12 Database searches have shown the region between OTC and dJ109C12 to be approximately $2.4 \mathrm{Mb}$ and to contain seven genes (NCBI, ${ }^{25}$ fig 3). Two known $\mathrm{X} / \mathrm{Y}$ homologous genes, $D F F R X$ and $D B X$, which escape $\mathrm{X}$ inactivation, are found to lie on consecutive BAC clones in this interval. ${ }^{26}{ }^{27} C A S K$ is known to be $\mathrm{X}$ inactivated. ${ }^{28}$ The $\mathrm{X}$ inactivation status of the other genes in this region is not known. The $\mathrm{Y}$ chromosome homologues of DFFRX and $D B X$ are adjacent to each other in Yq11.2 and in fact remnants of a $\mathrm{Y}$ homologue of $C A S K$ lie just telomeric of $D B Y$ (fig 3). Patients with deletions of the region on the $\mathrm{Y}$ chromosome containing DFFRY and DBY are infertile but show no signs of lymphoedema. ${ }^{7}$ This suggests that these genes are not likely to be involved in this aspect of the Turner phenotype, unless the $\mathrm{X}$ and $\mathrm{Y}$ homologues have distinct function. Proximal $\mathrm{Yq}$ has also been implicated in the Turner skeletal phenotype; however, evidence now suggests that SHOX alone may be important for skeletal abnormalities. ${ }^{15}$ The skeletal stigmata seen in the patients described by Barbaux et at and Tzancheva et $a l^{9}$ might be explained by haploinsufficiency of SHOX as all the patients described also have short stature. 
Deletions of Yp11.2 give rise to lymphoedema with the critical region between the pseudoautosomal boundary and sY45. ${ }^{10}$ The region between sY20 and sY45 is part of the Yp11.2/Xq21.3 homologous block with 99.6\% identity between the two chromosomal regions, and is known to contain two $\mathrm{X} / \mathrm{Y}$ homologous genes PCDHY and TGIFLY ${ }^{29}$ (unpublished results). The region between the pseudoautosomal boundary and sY20 is covered by one sequenced contig (GenBank nt_001609) $306 \mathrm{~kb}$ in size and contains a NAP pseudogene and three genes $S R Y, R P S 4 Y$, and $Z F Y$ (fig 3). All three genes have $\mathrm{X}$ chromosome homologues mapping to Xq26, Xq13.1, and $\mathrm{Xp} 21.3$, respectively. Although this might imply that $Z F Y / Z F X$ are candidates for the lymphoedema as they both map to the regions deleted in Turner patients, $Z F X$ is distal to $O T C$ and haploinsufficiency of $Z F X$ in the inherited Turner patients described ${ }^{22-24}$ was not associated with lymphoedema.

It is therefore postulated (1) that more than one gene may be involved in the lymphoedemic phenotype, and (2) that the genes on the Y which lead to lymphoedema (although they might be $\mathrm{X} / \mathrm{Y}$ homologous) may not be functionally homologous to the genes on the $\mathrm{X}$ (and vice versa). No deletion of a single locus on the $\mathrm{X}$ chromosome gives rise to lymphoedema, although deletion of the region between OTC and dJ109C12 appears more often to associate with this phenotype. Not all patients with this region deleted have lymphoedema and other patients have been described with lymphoedemic features and deletions elsewhere. ${ }^{3}$ This suggests that a gene in Xp11.4 may play a more dominant role in the aetiology of lymphoedema and other genes from both the $\mathrm{X}$ chromosome and perhaps autosomes may play a modifying role. This is not inconsistent with the lymphoedema resolving with age. It is possible that $V E G F-D$, mapping to Xp22 (fig 3), may play a modifying role. It is known to be a ligand of VEGFR-3 and mutations of this receptor have been found in patients with primary lymphoedema. ${ }^{30}{ }^{31}$ It is interesting to note that one of the key patients defining the critical region on the $\mathrm{Y}$ chromosome has an additional $\mathrm{Y}$ deletion in PAR2, which, unlike the Yp11.2 deletion, is present in the father. ${ }^{9}$ This patient's brother, who is not thought to have the Yp11.2 deletion, shows signs of cystic hygroma, which suggests that an additional gene in PAR2 may play a role in the phenotype.

No homology between the critical regions in $\mathrm{Xp} 11.4$ and $\mathrm{Yp} 11.2$ is seen. As all the genes in the critical region on the $\mathrm{Y}$ are $\mathrm{X} / \mathrm{Y}$ homologous it suggests that the $\mathrm{X}$ and $\mathrm{Y}$ homologues have different functions. It is already known for some such genes that the $\mathrm{X}$ and $\mathrm{Y}$ homologues may have different expression patterns. ${ }^{29}$ Further analysis of patient material will help to define more accurately the regions involved in the lymphoedemic phenotype. Patients such as the one described by Hasegawa $e t a l^{\beta 2}$ with no obvious deletions will be useful to analyse the candidate genes identified to elucidate the important genes involved in this phenomenon.
This work was funded by an MRC programme grant. We wish to thank Drs Charles Lee and Ian Roberts for expert help and advice with the FISH experiments. The authors also thank the following funding bodies for their current support: PIC (Pig Improvement Company) (CAB and CAS) and The Isaac Newton Trust (CAS).

1 Turner H. A syndrome of infantilism, congenital webbed neck and cubitus valgus. Endocrinology 1938;23:566.

2 Hook EB, Warburton D. The distribution of chromosomal genotypes associated with Turner's syndrome: livebirth prevalence rates and evidence for diminished fetal mortality and severity in genotypes associated with structural X abnormalities or mosaicism. Hum Genet 1983;64;24-7.

3 Ogata T, Matsuo N. Turner syndrome and female sex chromosome aberrations: deduction of the principal factors involved in the development of clinical features. Hum Genet 1995;95:607-29.

4 Ross JL, Roeltgen D, Kushner H, Wei F, Zinn AR. The Turner syndrome-associated neurocognitive phenotype maps to distal Xp. Am f Hum Genet 2000;67:672-81.

5 Jones KL. Smith's recognizable patterns of human malformation: genetic, embryonic and clinical aspects. 4th ed. Philadelphia: Saunders, 1988

6 Ferguson-Smith MA. Genotype-phenotype correlations in individuals with disorders of sex determination and devel-
opment including Turner's syndrome. Semin Dev Biol 1991;2:265-76.

7 Sargent CA, Boucher CA, Kirsch S, Brown G, Weiss B, Trundley A, Burgoyne P, Saut N, Durand C, Levy N, Terriou $\mathrm{P}$, Hargreave $T$, Cooke $H$, Mitchell $M$, Rappold GA, Affara NA. The critical region of overlap defining the AZFa male infertility interval of proximal Yq contains three tranmale infertility interval of proximal Yq contains

8 Barbaux S, Vilain E, Raoul O, Gilgenkrantz S, Jeandidier E, Chadenas D, Souleyreau N, Fellous M, McElreavey K. Proximal deletions of the long arm of the Y chromosome suggest a critical region associated with a specific subset of characteristic Turner stigmata. Hum Mol Genet 1995;4: 1565-8.

9 Tzancheva M, Kaneva R, Kumanov P, Williams G, Tyler-Smith C. Two male patients with ring Y: definition of an interval in Yq contributing to Turner syndrome. $\mathcal{F} \mathrm{Med}$ Genet 1999;36:549-53.

10 Ogata T, Tyler-Smith C, Purvis-Smith S, Turner G. Chromosomal localisation of a gene(s) for Turner stigmata on Yp. $\mathcal{F}$ Med Genet 1993;30:918-22.

11 Ellison JW, Wardak Z, Young MF, Gehron Robey P, Ellison JW, Wardak Z, Young MF, Gehron Robey P,
Laig-Webster M, Chiong W. PHOG, a candidate gene for Laig-Webster M, Chiong W. PHOG, a candidate gene for
involvement in the short stature of Turner syndrome. Hum Mol Genet 1997;6:1341-7.

12 Rao E, Weiss B, Fukami M, Rump A, Niesler B, Mertz A, Muroya K, Binder G, Kirsch S, Winkelmann M, Nordsiek G, Heinrich U, Breuning MH, Ranke MB, Rosenthal A, Ogata T, Rappold GA. Pseudoautosomal deletions encompassing a novel homeobox gene cause growth failure in diopathic short stature and Turner syndrome. Nat Genet 1997; 16:54-63.

13 Shears DJ, Vassal HJ, Goodman FR, Palmer RW, Reardon W, Superti-Furga A, Scambler PJ, Winter RM. Mutation and deletion of the pseudoautosomal gene SHOX cause Leri-Weill dyschondrosteosis. Nat Genet 1998;19:70-3.

14 Belin V, Cusin V, Viot G, Girlich D, Toutain A, Moncla A, Vekemans M, Le Merrer M, Munnich A, Cormier-Daire V. SHOX mutations in dyschondrosteosis (Leri-Weill synSHOX mutations in dyschondrost
drome). Nat Genet 199819:67-9.

15 Clement-Jones M, Schiller S, Rao E, Blaschke RJ, Zuniga A, Zeller R, Robson SC Binder G, Glass I, Strachan T, Lindsay S, Rappold GA. The short stature homeobox gene SHOX is involved in skeletal abnormalities in Turner syndrome. Hum Mol Genet 2000;9:695-702.

6 Kosho T, Muroya K, Nagai T, Fujimoto M, Yokoya S, Sakamoto H, Hirano T, Terasaki H, Ohashi H, Nishimura G, Sato S, Matsuo N, Ogata T. Skeletal features and growth patterns in 14 patients with haploinsufficiency of SHOX: implications for the development of Turner syndrome. $f$ Clin Endocrinol Metab 1999;84:4613-21.

17 Vollrath D, Foote S, Hilton A, Brown LG, Beer-Romero P, Bogan JS, Page DC. The human Y chromosome: a 43-interval map based on naturally occurring deletions. Science 1992;258:52-9.

18 Jones $M H$, Furlong RA, Burkin $H$, Chalmers IJ, Brown GM, Khwaja O, Affara NA. The Drosophila developmenGM, Khwaja O, Affara NA. The Drosophila developmenwhich escapes X-inactivation and has related sequences on which escapes X-inactivation and has related
Yq11.2. Hum Mol Genet 1996;11:1695-701.

19 James RS, Coppin B, Dalton P, Dennis NR, Mitchell C, Sharp AJ, Skuse DH, Thomas NS, Jacobs PA. A study of females with deletions of the short arm of the $\mathrm{X}$ chromosome. Hum Genet 1998;102:507-16.

20 Francke U. Random X inactivation resulting in mosaic nullisomy of region Xp21.1-p21.3 associated with heterozygosity for ornithine transcarbamylase deficiency and for chronic granulomatous disease. Cytogenet Cell Genet 1984;38:298-307.

21 Zinn AR, Tonk VS, Chen Z, Flejter WL, Gardner HA, Guerra R, Kushner H, Schwartz S, Sybert VP, Van Dyke DL, Ross JL. Evidence for a Turner syndrome locus or loci at Xp11.2-p22.1. Am f Hum Genet 1998;63:1757-66.

22 Massa G, Vanderschueren-Lodeweyckx M, Fryns JP. Deletion of the short arm of the $\mathrm{X}$ chromosome: a hereditary form of Turner syndrome. Eur F Pediatr 1992;151:893-4. 
23 Zinn AR, Ouyang B, Ross JL, Varma S, Bourgeois M, Tonk V. Del (X) (p21.2) in a mother and two daughters with variable ovarian function. Clin Genet 1997;52:235-9.

24 Adachi M, Tachibana K, Asakura Y, Muroya K, Ogata T. $\operatorname{Del}(\mathrm{X})(\mathrm{p} 21.1)$ in a mother and two daughters: genotypephenotype correlation of Turner features. Hum Genet 2000;106:306-10.

25 Pusch CM, Zeitz C, Brandau O, Pesch K, Achatz H, Feil S, Scharfe C, Maurer J, Jacobi FK, Pinckers A, Andreasson S, Hardcastle A, Wissinger B, Berger W, Meindl A. The complete form of X-linked congenital stationary night blindness is caused by mutations in a gene encoding a leucine-rich repeat protein. Nat Genet 2000;26:324-7.

26 Jones MH, Khwaja OSA, Briggs H, Lambson B, Davey PM, Chalmers J, Zhou CY, Walker EM, Zhang Y, Todd C, Ferguson-Smith MA, Affara NA. A set of ninety-seven overlapping yeast artificial chromosome clones spanning the human Y chromosome euchromatin. Genomics 1994 24:266-75

27 Lahn BT, Page DC. Functional coherence of the human Y chromosome. Science 1997;278:675-80.
28 Carrel L, Cottle AA, Goglin KC, Willard HF. A firstA some Proc Natl Acad Sci USA 1999;96:14440-4.

29 Blanco P, Sargent CA, Boucher CA, Mitchell M, Affara NA. Conservation of PCDHX in mammals; expression of human X/Y genes predominantly in brain. Mamm Genome 2000;11:906-14.

30 Achen MG, Jeltsch M, Kukk E, Makinen T, Vitali A, Wilks $\mathrm{AF}$, Alitalo K, Stacker SA. Vascular endothelial growth factor D (VEGF-D) is a ligand for the tyrosine kinases VEGF receptor 2 (Flk1) and VEGF receptor 3 (Flt4). Proc Natl Acad Sci USA 1998;95:548-53.

31 Karkkainen MJ, Ferrell RE, Lawrence EC, Kimak MA, Levinson KL, McTigue MA, Alitalo K, Finegold DN. Missense mutations interfere with VEGFR-3 signalling in primary lymphoedema. Nat Genet 2000;25:153-9.

32 Hasegawa T, Ogata T, Hasegawa Y, Hondo M, Nagai T, Fukushima Y, Nakahori Y, Matsuo N. Coarctation of the Euk . surface anom for the possible impairment of a putative lymphogenic gene(s) for Turner somatic stigmata. Hum Genet 1996;97:

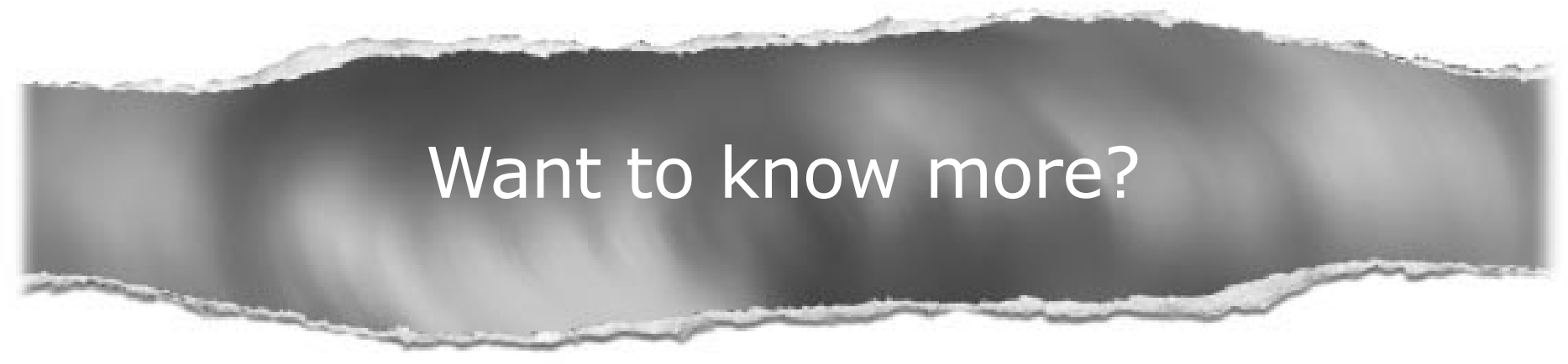

Data supplements

Limited space in printed journals means that interesting data and other material are often edited out of articles; however, limitless cyberspace means that we can include this information online.

Look out for additional tables, references, illustrations.

www.jmedgenet.com 